\title{
Aspects of theories, frameworks and paradigms in mathematics education research
}

\author{
Dorian Stoilescu \\ Centrefor Educational Research, School of Education, Western Sydney University, Penrith, Australia \\ For correspondence: d.stoilescu@westernsydney.edu.au
}

\begin{abstract}
This article discusses major theoretical debates and paradigms from the last decades in general education and their specific influences in mathematics education contexts. Behaviourism, cognitive science, constructivism, situated cognition, critical theory, place-based learning, postmodernism and poststructuralism and their significant aspects in mathematics education are discussed. In a discussion that limits its size to that of one article, my main goals are to outline the main tendencies and debates that operate on various educational contexts and theoretical assumptions - the way they interfere and challenge each other and their connections to mathematics education research.
\end{abstract}

Keywords: paradigms; theoretical frameworks; mathematics education research.

\section{Introduction}

Theories can be viewed as virtual reality systems that helps practitioners connect to day-to-day realities. Here, I discuss theoretical frameworks and paradigms that play important roles in mathematics education (Ernst, 1992), where some characteristics remain unclear or not enough understood and many debates are still left. Within a broad area of frameworks, theoretical paradigms, and ideological and practical issues, there are many specific questions that arise on placing these perspectives into various mathematics education contexts, and the following discussions are meant only to make brief points and should not be viewed as an exhaustive list. What is the nature of mathematics and mathematics education and how can we set adequate framework and productive paradigms for research? What is the nature of teaching and learning mathematics and how can we interpret outcomes through our existing paradigms? What are the aims of mathematics education research and how can paradigms help? How should researchers and teachers approach various mathematical educational contexts and paradigms in which mathematics practices take place?

These inquiries are some specific important and persistent questions in mathematics education research that remain unanswered. Mathematics education research is linked with individuals, their interests, thoughts, interactions, countries, cultures, communities, and school curricula that legitimate certain practices. Therefore, in discussing the most significant influences and orientation in mathematics education research, it is vital to review theoretical presumptions, frameworks, and paradigms and explore their importance.

While a few researchers such as Kilpatrick (1992) believe that mathematics education research is not linked with any one theory, there is a general agreement that researchers need to consider the influence of theoretical frameworks (Cobb, 2007; Ernest, 1998; Lester, 2010). As Lester (2010) asserts, "the notion of a research framework is central to every field of inquiry, but is the least understood aspect of the research process" (p. 458). There are many theoretical frameworks coming from different traditions: mathematics itself, psychology, neurology philosophy, history, environmental science, sociology, cultural studies, or logic that have influenced mathematics education research. 
In this paper, I will discuss some of the most well established paradigms from the last decades of education and their impacts for mathematics education research. I will describe major topics in mathematics education research that were approached through new paradigms. More exactly, the following theoretical frameworks will be examined: a. behaviourism; b. cognitive science; c. constructivism; d. critical theory; e. situated learning; g. place-based learning education; and h. postmodernist theories in education. This article is a more than a simple literature review and less than an essay. While an exhaustive discussion of these paradigms is not within the scope of this paper, the main goal is to provide some glimpses and chief points of theoretical alignment for researchers and educators in mathematics education.

\section{The Evolution of Behaviourism in Mathematics Education}

Behaviourism is perhaps one of the oldest and most well-known theoretical orientations in education. Coming from psychology, the behaviourists claim that instruction and learning, among other domains of human activities, is based on repetition and reinforcement. Watson (1926) and Skinner $(1953,1985)$ consider that the knowledge can be obtained from adequate instruction, is driven by objectivity and, as such, every instructional outcome is measurable. In educational contexts, behaviourists claim that the effects of instruction are totally observable (Estes \&Suppes, 1959; Skinner, 1954) and display quantifiable changes in students' behaviours.

According to behaviourists, the main aspect of instruction consists of the transmission of knowledge from teachers to students (Skinner, 1954). Major academics contributing to behaviourism, in fact provide a major assistance to the development of mathematics education. For instance Skinner's (1957) theories of conditioning, Bloom's (1956) Taxonomy of Educational objectives and Gagne's (1967) work on learning hierarchies have been highly influential upon mathematics teaching and teacher training programmes. Behaviourists consider that, by using universal instructional strategies and rules, through previously established didactic steps, students are able to learn something specific that otherwise they could not learn by themselves. In behaviourism, there are no aspects of studying instruction related to internal states of mind like thinking, emotions, attitudes, or emotions. As well, in the study of instruction and learning, the behaviourists regard instructions only as covert speeches (Skinner, 1957), as they do not consider in their research any aspects of mental life or any internal state of mind (Skinner, 1985).

Some of the negative aspects of this movement were: the narrow use of behavioural objectives, outcomes-based education, mastery learning, programmed learning, an over emphasis on skills drill and practice, and a focus on large scale skills based testing (often multiple choice questions) as opposed to testing understanding and the application of knowledge. In this view, mathematics was seen a predefined set of rules (Eisenberg, 1975). An educational consequence for mathematics educators was the belief that mathematics can be transmitted by inoculating the right knowledge and discourse at the right time. As such, mathematics education was seen as a linear way to provide students with already established theories, knowledge paths and experiences (Gagne, 1965). From the behaviourist perspective, mathematics education was seen as having a teacher-centric approach that contains a static set of mathematical rules. As such, students were expected to respond by answering with a similar discourse. The process of learning was expected to take place by going from concrete to abstract and from analysis to synthesis in a pre-established pathway (Gagne, 1965).

This assumption that everything in mathematics education is measurable was vigorously criticized by the research community. In particular, the ignoring of internal states of mind was widely criticized by Chomsky (1959) and Gardner (1985). For example, some mathematics educators such as Eisenberg (1975) claimed that behaviourism destroyed any authenticity, creativity and intellectual passion. In fact, Eisenberg alleged that the behaviourism approach represents a major cause of present mathematical illiteracy. Influenced by critics and researchers from various areas such as processing theory, cognitive science, neurologists, constructivists, critical theory and the works of Polya, Piaget and Vygotsky, behaviourism drastically changed by starting to accept that not everything was observable and that learning and instruction require more complex cognitive states of mind and 
processes (Berlyne, 1965). The second wave of contributions to this theoretical paradigm, the neobehaviourists, as Suppes (1975) outlines, showed more complexity:

Behaviorism as a fundamental methodology of psychology is here to stay, but the room that it occupies is sufficiently large to admit a dazzling array of mental furniture. Clear recognition that there is mental furniture inside the room is why the sign over the door should now be changed from behaviorism to neobehaviorism.

Many large projects at provincial, state, and national level were designed based on these behaviourist presumptions, as this theoretical model was extremely popular in 1950s and 1960s in the US. Despite its shortcomings and critics, the theoretical framework was reformed and still retains an important place nowadays heavily influencing large scale projects as No Child Left Behind (NCLB) orCommon Core/Race to the Top (CC/RttT) in the US.

One of the important research topics in mathematics education taken further by behaviourists was the analysis of errors in various types of problems: operation with whole numbers (Thorndike, 1922), fraction, geometry, algebra, or calculus. For instance, American behaviourist researchers tried to perform error analysis from curricular and operationally exclusive perspectives. While in North America, behaviourism was the dominant orientation (Arthur 1950, Roberts 1968), European research developed different strategies based on different theoretical orientations, such as that of Polya (1957), Piaget, or German mathematics educator Radatz (1979). Radatz's ideas of investigating mathematical errors were different from behaviourists and were related more to the theory of information as he explored mathematical deficiencies in multifold directions: language, space, prerequisite facts and concepts; associations and flexibility/rigidity of thinking, applying relevant rules or strategies. In addition, Erlwanger, (1975) proved that behaviourist instruction does not necessarily produce understanding in children's conceptions of mathematics.

\section{Cognitive Science in Mathematics Education}

Cognitive science was increasingly popular by the end of 1970s (Gardner, 1985). It started with Bruner (Bruner, Goodnow\& Austin, 1956; Bruner 1960) and the criticisms of Chomsky (1959) against the behaviourist views of Skinner. In the development of cognitive science, researchers distinguished three distinct generations (Howard 2010; Nagataki\& Hirose, 2007). In the first generation, known as the classical theory of Artificial Intelligence (AI) (Nagataki\& Hirose, 2007), the main focus was on the physical manipulation of symbols (Gardner, 1985; Mayer, 1996; Nagataki\& Hirose, 2007). In this view, learning was regarded as the recall of stored information and, therefore, first generation of cognitivists offered a rigid view of constructing expertize.

According to Mayer (1996), the focus was on logic-based operations, as the main ontological view was that mind displays performances similar to a computer (Klein, 2007). As such, obtaining knowledge was viewed as part of processing information theory or, at best, as having some semantic memory approaches. From this viewpoint comes the perspective that teaching mathematics needs to provide stable and well-defined educational strategies that offer capabilities for a) storing and retrieving knowledge for learning activities, b) manipulating diverse numerical, geometrical and logical symbols, and c) designing flexible strategies of problem solving. The first wave of cognitivists considered that, over time, the knowledge terms, operations and symbols would not change their meaning. In this view, the language used to manipulate these symbols and operations was considered as expressing ideas and thoughts that were considered pre-existent. Strongly influenced by behaviourism, mathematical discourse was viewed as a thinking process, with few connections to internal states of mind (Schoenfeld, 1987). Some important topics for the first-generation of cognitive science included mathematical expertize and improving capabilities in problem solving. One of the topics in mathematics education research that can be classified in this first-generation of cognitive topics is the map concept, a topic that started to be developed in 1970s (Novak, 1980).

Different from the first-generation of cognitive science, the second-generation of cognitive science was called connectionism. Connectionists review the process of expertize as a flexible and organized ensemble of human cognitive approaches, close to what is deemed as the central process of cognition 
(Klein, 2007). Structures and processes, once assumed to underpin cognition with items such as formal logic and concepts, are still assumed to exist, but being derivative of rudimentary processes and seen as peripheral or exotic. In contrary, concepts such as analogy and distributed cognition are increasingly thought to gain importance and became common for learning.

Bruner (1990) considered cognitive theory as radically different from the former framework of behaviourism. For him, cognitive theory is a revolutionary approach oriented to meaning making and not only as a theory of the transmission of information. The major research area for the second generation of cognitivists was the study of learning and factors and aspects that influence it. For Bruner (1990), learning reflects not only receiving and delivering a message, but also establishing a context in which a certain kind of educational acts take place. According to Bruner (1990), adequate processes of learning create adequate representations of cognitive structures for representing knowledge in memory for the learner. For the first time, sociocultural aspects of learning were considered, as connectionists viewed learning to communicate as an intrinsic way of learning, as a path of becoming accustomed to school and community, in order to approach, exchange and be part of a specific culture (Bruner, 1990).

Connectionists considered that the process of instruction needed to include aspects of classroom and group interactions. In order to study learning, connectionists discussed complex topics such as engaging students in learning, facilitating ways of having students interact with each other, enhancing abilities in helping one another, and developing skills of explanation (Webb \&Farivar, 1997). This dynamic joint construction of meanings signified commitment by educators to create a common ground for shared understanding. The generation of meaning in connectionism was studied in many research projects that had either cooperative or collaborative strategies. These aspects of collective meanings that were developed from group interactions were intensely scrutinized in the research literature (Koschmann 1999; Putnam \&Borko, 2000). For instance, Koschmann (1999) noticed that in order to study the way meaning is generated, a variety of concepts had been developed including intersubjectivity, grounding, co-construction, sense making, and conceptual change.

According to connectionists, mathematical instruction can be viewed as helping students form more significant and complex learning structures on knowledge of solving strategies than before starting the process of instruction (Cobb, 1988). By solving mathematical problems, students develop special structures such as metacognition and problem solving strategies. This also means an emphasis on developing other concepts such as intersubjective capabilities, and on exploring paths students interact with each other and enhance their expertise in multiple contexts. Developing problem solving strategies is more than developing a set of techniques and algorithms to solve a specific class of problems. Metacognition helps to understand how learners self-regulate their learning, by adapting their complex and various types of strategies and problems, and being capable to use these in manifold contexts. In this way, the role of the mathematics teacher is to assist students in the process of restructuring and configuring mathematical knowledge, in order to help them to achieve problem solving skills and strategies and build metacognition.

For a group activity to be successful, Palinczar (1998) asserts that it is important that "responsibility is shared, expertise is distributed, and there is an ethos for building procedural ideas" (p. 365). Therefore, teachers play an important role in facilitating adequate distribution of responsibility and expertize. Palincsar (1998) noted that cognitivists acknowledged the multiple aspects of the social dimensions of learning: "thought, learning and knowledge are not just influenced by social factors but are social phenomena" (p.349). In consequence, children should be actively engaged in problemsolving, in order to see themselves as part of a specific culture of solving problems, and not just being outsiders trying to solve problems different from their community. This had important consequences for mathematics education if educators want to see their students become confident and passionate in approaching problem solving. In this sense, solving problems as group activity could help students become motivated and could give them skills to share and build responsibility and expertize. In this context, it is important to observe how disequilibrium and equilibrium moments during solving problems appear and how groups are dealing with them. In the new cognitive paradigm, disequilibrium is replaced by forces that contribute to the advancement of the knowledge. 
The importance of cognitive conflict when learners are confronted with misconceptions was frequently emphasized in mathematics education. For instance, Smith, di Sessa and Roschelle (1994) advise the fostering of an extensive and gradual set of exchanges of knowledge from misconceptions to expert concepts:

The goal of instruction should be not to exchange misconceptions for expert concepts but to provide the experiential basis for complex and gradual processes of conceptual change. Cognitive conflict is a state that leads not to the choice of an expert concept over an existing novice conception but to a more complex pattern of system-level changes that collectively engage many related knowledge elements (p. 154).

For the second generation of cognitivists, in the process of mathematical instruction, the content and the learning of mathematics are not neutral. Methodologies vary for connectionist scientists. In mathematics education, there is no methodology in place for all cognitive science approaches (Schoenfeld, 1987). Different types of pedagogical approaches such as simulation model or idealized models might be attempted. Instruction is viewed as a cognitive program that makes intellectual constructs that emulates the process of solving problems. As such, for Schoenfeld, the process of problem solving is not only description, but prescription as well.

Still, the second generation of cognitive science did not depart enough from Cartesian models of thinking. The first two generations did not consider systematically the particular aspects of human intelligence related to embodiment (Nagataki\& Hirose, 2007). It was the third generation of cognitivists who explored the interrelations of cognitive aspects of human intelligence between body and mind (Nagataki\& Hirose, 2007). Philosophically and theoretically, their work is highly inspired by the works of phenomenologist thinkers such as Husserl, Heidegger and Merleau-Ponty. They consider aspects of embodiment such as affectivity, motivation, passion, emotions, or anxiety should be consistently studied.

More recently, in the last decade, neuroscience in mathematics education has added one of the latest developments in mathematics education research. We have nowadays mathematics education research linked with the research from various disciplines of neuroscience. In the last decade, several neuroscience researchers (Campbell, 2010; Delazer et al., 2005; Lee et al. 2007) have shown great potential for extending embodied cognition research theories to various developments of neuroscience, in order to explore more insights into how people learn and teach mathematics. For instance, in comparing the processes of rote learning and learning for understanding in similar mathematics classes, Delazer et al. (2005) found that, although the pre-tests and post-tests showed similar results, the brain patterns of the students from the learning for understanding class had more complex brain patterns than the students who were placed in the rote learning class. Unfortunately, for the scope of the present paper there is no space to detail these recent discoveries. However, overall, even though research in neuroscience mathematics education is still at a beginning stage, the outcomes from the last decade in neurological research have potential to show great benefits for mathematics education researchers. Further, connections to research in teaching and learning mathematics are expected to improve the outcomes of this research framework.

\section{Constructivist Perspectives in Mathematics Education}

This theoretical framework has been treasured as being a major contributor to educational theories in mathematics education (Ernest, 2010; Rowlands \& Carson, 2001). Constructivism is an epistemological approach that considers that knowledge and meaning are generated from interactions between people's actions, experiences, and their subjective states of mind. For Von Glasersfeld (1991, 1995), one of the major contributors to constructivism, learning is active, as "knowledge is the result of a learner's activity rather than of passive reception of information or instruction" (Von Glasersfeld, 1991, p. xiv). Knowledge, considers Piaget (1950), is internalized by learners through processes of accommodation and assimilation. The main idea behind constructivism is that "understanding is in our interactions with the environment...We cannot talk about what is learned separately from how it is learned" (Savery\& Duffy, 1995). There are major projects and institutes from many countries from Europe and Americas that have constructivist approaches. 
Although it started as a theory of learning, it attempted to become a pedagogical theory, and combines now an approach to synthesizing personal knowledge, social knowledge, and scientific knowledge (Ernest, 1998). In particular, constructivism has an important role in many areas of education, social sciences and science.

Two of the main pioneers in developing the constructivist theory in education are Piaget and Vygotsky. Although being categorized in the same constructivist paradigm, their works are widely different. Some researchers views their work as complementary, while other researchers consider that their perspectives offer comprehensive dissimilar understandings about the role of teaching, the role of playing, and the importance of errors in learning (Pass, 2004). The constructivism based on Piaget's work has mostly a psychological and individualist perspective. In Piaget's work about child development, young children's ways of inquiry and acquiring knowledge are presented as radically different from those of adults (Piaget, 1969). Also, the role of teaching is different for Piaget, as the teacher is viewed only a diagnostician and not an instructor involved in providing new content, while for Vygotsky (1980) the teacher plays an active role in instructing and shaping children's knowledge.

For Piaget, the interactions with peers are appreciated as producing better experiences than interactions students-teacher. As to the role of playing, for Piaget the role of playing was only acceptable at an early age, while for Vygotsky the role of playing was deemed to provide great experiences at different age levels (Pass, 2004). Another important difference is taking in the role of errors. While Piaget considers errors as tolerable, for Vygotsky these are something damaging the educational process, painful and highly recommended to be avoided. While neither considers errors as important in developing learners' knowledge, Piaget acknowledges a greater role for errors in the process of instruction. As such, Piaget considers errors as part of learning outcomes and asks teachers to establish a clear distinction between errors and failures. For him, errors are viewed only as intermediary steps towards finding the right answer and are treated as intermediate states of knowledge. For Vygotsky, errors have exclusive negative connotations and are considered as failures that are happening when the other instructional partners (e.g. the teacher or the colleagues) are not doing the job properly.

Based on different emphases, today there are many types of constructivism: social, radical, postmodernist, critical, to name a few. For instance, Piaget's work is regarded as leading towards radical constructivism (Von Glasersfeld, 1990, 1991, 1995), while Vygotsky's opinions are converging toward social constructivism (Ernest, 1998). Having various and very dissimilar facets, these eclectic aspects of constructivism inevitably triggered some researchers to criticize its wide-ranging views. For instance, Nola (1997) criticized constructivism for its uncritical aspects and confusions that are often found in its core structure. Therefore, he asked to differentiate between the epistemic and empirical aspects of constructivism, between pedagogical and psychological aspects. Slezak (2000) considers that while constructivism is a trendy paradigm, the practical benefits of constructivist pedagogies are seriously under-performing and under-delivering their expected promises. Kirschner, Sweller, and Clark (2006) suggest that more structure and guidance methods, such as problem-based learning, experiential learning or inquiry-based learning are required.

Researchers considered the divergent aspects of constructivism as being appropriate and according to our contemporary world scientific methodology. For instance, Staver (1998) defends constructivism by arguing for the significance and soundness of its polymorphic perspectives and actions. He suggested that the constructivist critics ought to accept the perspective that truth presented in a theory should not be rigidly requested as one-dimensional push for coherence. As such, with constructivism, we should accept its multiple approaches as a contemporary way of achieving relevance. For Staver, constructivism is a rejection of solipsism and supports modern approaches from the modern neurophysiologic theory reviewing the brain as a parallel data-processing organ in which meaning-making takes place in both individuals and communities. Therefore, if this paradigm performs divergent perspectives, this should not misguide us in viewing constructivism as missing truth and relevance.

In fact, constructivism is credited as being capable of exploring multifaceted and interconnected 
domains of knowledge, directions and values that influence individuals and groups: learning, teaching, cognition, science, society, ethics, politics, or even our worldview (Ernst, 1998). Therefore, constructivism is a major contributor that changed researchers' views on the way students can understand, learn, interact, and acquire new knowledge. Constructivism is strongly connected to other theoretical paradigms such as cognitive science (Palincsar, 1998). Since all cognitive structures use to some extent constructed representations at individual levels, all constructivists theories use to some extent some forms of cognitivist science.

In mathematics education, constructivist educators provided important contributions by challenging teaching-centred model, the lack of attractiveness in the mathematical content, the excessive formalization without mathematical relevance, and the privation of emotional activities in mathematics classrooms. In their pledge to make mathematics more accessible for students, constructivists made mathematics lessons more participatory and gave increasing importance to cooperative and collaborative learning strategies. They encouraged interactive learning in complex situations and solving relevant problems in social contexts. In mathematics education research, constructivists reshaped the main themes and topics according to constructivist philosophy. For instance, while for behaviourists the analysis of errors was a cold, mechanical and, at best, statistical approach to analyse the generation of mistakes and misconceptions, constructivists freely used errors as a path to improving students' understanding of mathematical concepts. Similarly, problem-solving strategies were entirely overhauled, as previous approaches presented only a summary of ideas towards the main steps of solving problems. However, as mathematics educators acknowledged, these descriptions were quite reductionist, as they did not help enough for students to build expertize in solving extended classes of problems. As constructivist mathematics educators acknowledged, more personalized, interactional and psychological aspects were involved in describing and embodying learning expertize in solving problem. In approaching problem solving, there were used a wide category of strategies in Polya (1958), Garufalo and Lester (1985), Van Hiele and Van HieleGeldof (1958), and general educators such as Piaget (1950) and Vygotsky (1980).

\section{Critical Theory in Mathematics Education}

The foundations of critical theory stand in evaluating and criticizing society, culture and civilization, in order to reveal, describe and critique social inequality. Critical theory is considered an influential paradigm in social sciences and humanities. This theory focuses on how members of the society create, influence, negotiate, and reinforce social and power relationships. Critical theory means going farther than a passive notice of patterns of domination embedded locally, nationally or globally. Proponents ask for a radical engagement with community and society in order to fight social inequity and unfairness (Giddens, 1991). Starting in the 1930s, the originators of critical theory were the Frankfurt School and had exclusively Marxist orientations. The most important contributors from the group were Adorno, Horkheimer and Marcuse. They expanded their research in society in order to explore ways in which social power relationships and inequity shape various area such as the economy, finance, technology, commodities, mass media, and education. There are many areas of critical theory that impacted on education such as critical pedagogy, feminist education, antiracist education, globalization in education, multicultural education, intercultural education, postcolonialist education, and cultural studies in education.

In education, critical pedagogy is a radical critique of schools and communities, environments, schooling administrations, curricula, and educational policies. A great number of educationists such as Freire, Giroux, Aronowitz, McLaren, Kincheloe, Apple, and Steinberg have made significant contributions to this theoretical. For instance, Freire (1990) identified the way students are traditionally forced into what he calls banking education. In banking education, the role of the teacher is the fountain of knowledge, the personification of the Truth or, in other words, thedominant discourse. Students are deemed to be passive recipients, without any decision-making choice or agency, and, as such, run the risk to remain alienated from the authentic educational outcomes of schooling. Many of them would remain unengaged and unempowered by the potential of knowledge and skills that education might offer. Thus, they are left disaffected and marginalized in the current educational and social systems. As such, these students are deemed to leave the schools at an early 
stage and to have small chances of attaining wellbeing, reasonable jobs, wealth, and social privileges, later in their lives.

Bernstein (1996) shows that in education, knowledge and power interconnect and influence each other in very subtle and concealed ways. Kincheloe (2005) advises that knowledge should not be treated by educators as a commodity and that students should not be trained as knowledge workers in classrooms, as this form of knowledge is seen as a corporatist path, withdrawn from civic and community values. Apple (2000) shows that education is controlled by marketization rules, rigid standards, and lack of equity in political, economic and social cultural power, where the emphasis is on competition and testing the basic skills in mathematics, literacy and technology, and with reduced time for social justice and ethical issues. Giroux (1983) showed the way a hidden curriculum influences schooling nowadays. This is often an under-the-radar curriculum that has negative messages and connotations for students' aspirations, as instead of making them aspire to intellectual development, it reinforces existing social inequalities, by educating students to accept present inequities and barriers of race, gender, class and social status.

There are several strong critics of critical theory. Many of them including Finn (1990) believed that critical theorists lacked the determination and ability to transform their critiques into meaningful actions. One of the people that acknowledged that the lack of practicality might negatively influence critical theory outcomes was Goodman (1992). He cautioned about the danger that any theory, especial critical theory, can pose toxic challenges when it is not rooted in practice. According to Goodman (1992), a theory that lacks a practical foundation is "at best a self-indulgent expression ... at worst a form of psychic oppression" (p.166). In the 1980s critical theory started losing its edge, its radical novelty and people's interest. Habermas $(1984,1992)$ is credited with reshaping and invigorating critical theory with new methods, orientations, approaches and ideas, as he advanced more reliable strategies, aimed away from a totalizing critique and moving toward reinforcing liberatory practices characteristic of communicative activities in society.

Critical pedagogy has been approached by numerous educationalists, as a way to empower marginalized students and teachers working to combat injustice and paucity in communities and schools. In classrooms, the process of mediation takes place between learners, teachers and the curriculum as knowledge, opinions, and negotiating values. By displaying disempowerment of a great number of students and scrutinizing the disconnections of school curriculum from the day-today life activities, Freire (1990) initiated a vigorous criticism against traditional education. In the same way, Apple (1992) believes that the reliance on rote aspects of instruction and on crafted phrases that try to avoid any criticisms reproduce the present authoritarian structures of domination and is toxic for education (Apple, 1992). In fact, authoritarian educational systems restrict dialogic interactions since they might foment resistance (Giroux, 1983). As well, sometimes the abstract speech of mathematics is delivered as a way to perpetuate lack of knowledge and maintain inequities for many students (Apple, 1992). These ideas have powerful explanations in mathematics education, where Apple (1992) accuses mathematics education as having a long history of alienating many minority students and students from low socio-economic backgrounds. Concrete speech translates quickly into action, which is why it is feared by oppressors and is fundamental to emancipatory pedagogy.

Many educators have developed critical theory approaches in mathematics education in order to improve the relevance and the role of mathematics education in schools and communities (Martin, 2010; Valero, 2004; Skovsmore\& Valero, 2008). For instance, Skovsmore and Valero (2008) affirm that solving mathematics problems for social benefits has multifold and powerful aspects and implications for communities. They emphasize that, while mathematics concepts and theories are often perceived as abstract and dry areas of knowledge, interpreting these results in adequate contexts might produce new insights and powerful consequences (Valero, 2004). These changes might occur as major benefits or damages for all domains of society. Thus, exercising mathematics in responsive ways resonates in many ways to exercising democratic power. Critical pedagogy has a substantial role in finding appropriate ways to teach mathematics education, in order to empower students and remains an important goal in providing ways of understanding, action and changes for various social issues (Oakes \& Muir \& Joseph, 2000). For instance, problems around industrial products and prices, 
problems involving credit card consequences, are financial problems that help students understand social aspects of life and their complex consequences. Therefore, it is important that these mathematical problems be deployed in ethical and responsible ways, in order to offer an adequate understanding of the problem and its social aspects. As such, it is important to avoid decontextualized mathematical ideas and problems. Instead, mathematical methodologies should offer insights and debates about solving mathematical problems and designing various mathematical models, and understanding their social, environmental, ethical, and citizenship aspects, as well as their impact and consequences.

\section{Situated Learning in Education}

Situated learning theory emphasizes that learning and cognition are fundamentally situated phenomena (Brown, Collins \&Duguid, 1989). With respect to the main views of pedagogy, situated learning theory delineates four principles: (1) action is grounded in the concrete situation in which it occurs; (2) knowledge does not transfer between tasks; (3) training by abstraction is of little use; and (4) instruction must be done in complex social environments. Thus, situated learning theory is less concerned with memorization and most with hard to predict decisions and perceptions across complex educational contexts. In this view, educators are directed to avoid treating knowing and doing as separate entities, as the majority of today's schools do. Situated learning theory considers that transfers of task-based learning are important and critical for successful learning. When applied to a new task, learning is highly influenced by multiple perspectives and, therefore, the paths and successfulness of solving the new task should not be taken for granted. As such, Brown, Collins and Duguid (1989) maintain that knowledge transferability is limited from one context to another. Therefore, learning is more successful if it takes place in a specific cultural and social context that fits with the desired educational outcomes. This is achieved by participating in learning activities connected to day-to-day sociocultural experiences, where learners can achieve better results and improve their motivation and learning experiences.

Researchers such as Anderson, Reder and Simon (1996), Brown, Collins and Duguid (1989), and Greeno (1998) see individual activities as acts of participation in a community that is evolving in time. Brown and Duguid (1995) assert the importance of participation in classrooms as a way to build links between learners and the world through social practice. They see classroom participation being usually unproductive, as an exchange of ideas is often ignored and not fully understood. As such, defining an adequate type of climate in classrooms remains challenging. For this reason, designing various models of classrooms communities was very important for situated learning theorists. Several types of communities were created and designed for various purposeful situated learning outcomes.

From these, the most important are communities of practice (Lave \& Wenger, 1991), community of learners (Brown \&Campione, 1994), and knowledge building communities (Scardamalia\&Bereiter, 1994). Communities of practice, perhaps the most adopted model of situated learning communities, was designed by Lave and Wenger (1991), as a place where novices are initiated by other members of the community, through getting involved in various, multiple and complex situations, activities and practices. A community of practice contains more than intellectual values and it needs to make sense of its heritage, belongings and purposes. For Wagner, learning is not as much associated with the internalization of experiences, but rather to the process of participation in the community. This type of learning was coined by Lave and Wenger (1991) as legitimate peripheral participation and is explained as follows:

Legitimate peripheral participation is not itself an educational form, much less a pedagogical strategy or a teaching technique. It is an analytic viewpoint on learning, a way of understanding learning. We hope to make it clear that learning through legitimate peripheral participation takes place no matter which educational form provides a context for learning, or whether there is any intentional educational form at all. Indeed, this viewpoint makes a fundamental distinction between learning and intentional instruction. (p. 40)

Situated learning and social construction theorists also believe that learning is necessarily a social and dialogical process in which communities of practitioners negotiate the meaning of phenomena. This 
aspect is very important and should be specifically considered in mathematics education (Boaler, 1999). This emphasis of learning in community is a welcome alternative to formal instruction in mathematics education, as, unfortunately, many pedagogical approaches in mathematics education often proceed to decontextualize learning experiences and rather require abstract knowledge without any relevance to children's cultures and experiences (Boaler, 1999). Therefore, learning should be shared within a community of practice that is involved in the learning process and not pursued by isolated individuals (Wenger, 1991).

Cobb and Hodge (2002) use constructivism in mathematics education through communities of practice. They ask educators to start investigating local mathematical communities such as in the home, school, and neighborhood in order to empower students to have access to high levels of mathematical reasoning and to improve their self-confidence as capable mathematical problem solvers. As well, they suggest that using constructivist approaches, teachers can investigate barriers of confidence and offer ways of empowerment. As well, Cobb and Hodge (2002) shows that communities of practice need to extend their problem solving expertize and participation by contributing in various non-local contexts, from district to global level.

\section{Place-Based Learning in Mathematics Education}

Place-based learning is defined by combining simultaneously both social and natural aspects of the environmental education (Smith, 2002, 2007) and seen as having the potential to go beyond constraints of regular public school. Some researchers, such as Knapp (2007) and Gruenwald (2003), link place-based learning to a number of related educational approaches that connect local communities with schools, such as situated learning, critical theory, problem-based learning, project-based learning, contextual teaching and learning, service learning, and civic education. However, place-based learning has a unique commitment to connecting learning and teaching between natural and societal aspects of local and communities. Aboriginal communities have a special role and are often involved, as these have their direct way of connecting with the elements of the Mother Nature.

A significant role in place-based learning is to give greater importance to performing the process of instruction in natural settings. To illustrate the depletion of practices of using natural environment in instruction and the need for place-based learning, Pyle (2001) argues that, while in 1940s, schools and universities implicitly used natural contexts for direct experiments, at the end of 1990's all studies in Biology and Environmental Education started to take place in classrooms. Therefore, the researcher proposed placing greater importance on educational outdoor, as a way to value natural settings and authentic experiences. This is why Pyle believes that nowadays place-based learning is more important than ever. Likewise, Loveland (2003) affirms that by reducing the exposure to social and natural issues, students often become disconnected to community problems and therefore suffer a lack of motivation and commitment. As such, place-based learning might have a great role in reducing the lack of motivation in schools, as it has the potential to increase students' motivation with local and community aspects and interests. Correspondingly, Smith (2002) considers that place-based learning may offer a framework that improves school connections to local communities, expands students' involvement in resolving community problems, and stimulates students' desire to learn. In place-based learning, the teacher is a learning participant with the community and helps with better understanding of the global picture, as a guide to the community, as a facilitator trying to adapt his or her students to various and interconnected challenges from different topics with the local practices. Place-based learning is also credited with connecting with native cultures from North America and Australia, by approaching holistic learning and an emphasis for the natural settings, local communities, authenticity and spirituality.

One important controversy in regard to place-based learning is its compatibility with critical theory. While some educators consider critical theory an important ally to place-based learning, there are others who consider these theories as incompatible with each other. For instance, by being compelled of the role of revealing inequities and social power that takes place over the environment, Gruenewald (2003) consider critical theory the main ally of place-based learning theory. However, 
Bowers (2008) believes the contrary, as he considers that Marxist theories and, in particular, critical theory, are disruptive and anthropocentric theories. Bowers claims that critical theory often treats human beings as environmentally decontextualized from reality and, as such, critical theory activists do not want to be held accountable for the environmental damage they have promoted. Also, he notes that often critical theorists, especially the Marxists ones, had considered indigenous cultures communities as inferior and were not connecting themselves with nature, authenticity and spirituality.

Some differences between situated learning and place-based learning are important to describe. On the one hand, in situated learning, the contextual space is recognized fundamentally as a theoretical perspective. On the other hand, placed-based learning is oriented towards valuing a specific place in a specific community. This place is not only a physical space but has a role in the local society and history of a particular community. Place-based learning does not advocate ignoring the formal educational standards regarding skills or content but integrating them and using them in an adequate moment and place.

An important role in place-based learning has to do with connecting children with natural contexts and local communities. Place-based learning researchers consider that the whole of nature and various fragments of the habitat can teach children numerous aspects of life and therefore place-based learning has the capability to reveal important aspects for understanding, resulting in a balancing deep knowledge, affectivity, and intellectual and social skills. For example, Raffan (1993) argues that, the land can spiritually be viewed as a veritable teacher. Similar, for Poirier (2004), the river might also be considered spiritual teacher.

Some researchers use special terms such as place-based mathematics education, place-based statistics education and ethnomathematics. For instance, Howley at al. (2011) explore aspects of teaching placebased mathematics education. They found that the abstract content of mathematics makes the teaching aspects of connecting nature, social context and mathematical content challenging. Different from place-based mathematics education, Showalter (2013) found that, due to the different nature of statistics where various aspects of reality and society are available, place-based statistics education might be easier to teach than place-based mathematics education. Groth (2007) found that statistics requires more experimental approaches and social interpretations, as it requires empirical collection of data, trying to find various interpretations anchored in day-to-day experiences and, as such, demanding to meaningfully analyze the consequences and implications of the statistical problem. Some researchers consider cases that connect place-based learning with ethnomathematics (Furuto, 2014). Ethnomathematics adds new social aspects into problems such as providing relevant historical and cultural contexts (D'Ambrosio, 2001). Topics often studied are exploring mathematical practices and cultures achieved by different civilizations from various historical periods. As such, ethnomathematics proponents see this discipline as a case of rethinking and renegotiating pedagogy, culture, history, ideology, and mathematical content in very diverse contexts.

Woodhouse and Knapp (2000) highlight a number of tendencies and benefits about the place-based learning in mathematics education. For instance, place-based learning emerges from the specificity of the place, acknowledges local and aboriginal cultures, and deals with multidisciplinary approaches. More exactly place-based learning often connects curricular areas from mathematics, science and society, and offers mindful connections between place, people and community. As mathematics education has been accused of traditionally excluding concrete day-to-day experiences, place-based learning has the potential to correct these perceptions, by offering ways of mathematical modeling for problems that are coming from practices by local communities, in order to make people actively involved in finding genuine solutions.

\section{Postmodernist Theories in Mathematics}

While the first hints of postmodernism appeared more than a hundred years ago (i.e. an article from Thompson in 1914), discussions about its importance, roles and directions are still ongoing. The movement encompasses heterogenic contributions from thinkers such as Foucault, Derrida, Deleuze, 
Guattari, Lyotard, Latour, Eco, Law, and many others. It is a general outlook that each postmodernist thinker has very few common viewpoints with others, as postmodernism is defined less as a coherent doctrine and more as an attitude towards reality, government, and academic traditions. More exactly, postmodernists do not believe we can secure a foundation of universality and general agreement on values, and are skeptical about the possibilities of finding objectivity and truth through mathematics, science, social sciences, or arts. Postmodernists reject the perspective and the concept of absolute truth, as they believe there are multiple truths and that establishing the facts are based exclusively on our interpretations, priorities and perspectives. As well, they reject the notion of grand narratives (i.e. interpretations based on religion, freedom, truth, and history or major thinkers such as Marx, Freud, and Darwin) and look attentively of how power and narratives influence and legitimate each other. They offer a pluralistic set of opinions, interpretations, multiple truths and knowledges that offer diversity, divergence, and sometimes contradictory views without canceling each other out.

There are many important directions in postmodernism. One of them is poststructuralism. It is a long debate whether poststructuralism is part of postmodernism or not, as most North American experts are advocates and most European experts are against this assertion. For poststructuralists, meaning is more than signs acting in a specific context. Poststructuralists are interested in scrutinizing the contradictions that take place between the formation of discursive networks and the formation of the subject. They focus on exploring the relationships between discourse and power. It gives up to idea that human being is a timeless essence or has a consciousness unrestrained by historical and political practices (Lankshear\& McLaren, 1993).

Another major orientation of postmodernism is called postmodernist critical theory. The proponents of this theory seek to replace monolithic modernist assumptions of critical theory about absolutes in history, society, nature of human beings, and power relationships, with postmodernist philosophical perspectives, which become the basis for emancipatory education. Among postmodernists in education, however, there are those who support goals of emancipatory education, even while they contend that the philosophical assumptions underlying these goals are incoherent and unsteady. The most prominent exponents of critical postmodernism are Giroux, McLaren, and Aronowitz.

While there is still a lack of focus in finding specific research topics, the theoretical consequences of postmodernist and poststructuralist theories for mathematics education are very important. As a major outcome, mathematics discourse is not viewed anymore as an objective one, with a stable set of rules and axioms and incidental from personal techniques and preferences. Instead, mathematics education is viewed more as a social discourse, and the mechanism of proofs are seen as the social practice of mathematicians.

\section{Final Discussions about the Role of Paradigms in Mathematics Education}

Although this article precludes any attempts to exhaust representation and discussions of general theories on mathematics education research as maximum as sketchy, I believe, however, that it made some judicious points. First, paradigms work as lenses, by giving us hints on how to connect real world aspects to mathematical topics and research tactics. Second, these theories are not simple gratuities or pure intellectual games. As I have argued, these theories did not appear and grew up in vacuum. In contrary, these theoretical frameworks grew up from various practical and philosophical problems, still contend each other, shared common areas from previous theories, and influenced mathematics educators in multiple ways. Third, it can be hard at times to delineate among various specific mathematical educational research practices. As it can be seen, there are no clear criteria for delimitations between paradigms. However, we should not make the decision to separate a first goal in our quest to research.

More recently, it can be noticed the way many important researchers combine different paradigms. For instance, Tall (2012) describes the Three Worlds of Representations of learning mathematics as follows: Embodied, Symbolic and Formal. By combining multiple perspectives and paradigms, such as cognitive science, constructivism, and situated learning, Tall' s work describes practical and reflective turns on approaching various thinking skills in understanding mathematics and problem 
solving and, as well, reflects on various ways of connecting divergent ways of thinking for improving mathematical learning expertize.

This paper did not offer a pre-established classification and hierarchy of values and topics. In contrary, I avoided attempting to describe clear borders between theories. While keeping some general criteria in mind is helpful, I would rather want to keep a critical eye on a practical approach of using these paradigms in a flexible way in order to be able to introduce them in their new relevant contexts. I hope this short paper might dispose more people to read more about the theoretical approaches and paradigms.

I discussed the ways paradigms are defined and how they influenced each other, but important questions still remain. What theory is useful and what paradigm is better to use in mathematics education research? For individuals and groups, each theory and paradigm plays a different role. As Lester (2010) mentioned, using paradigms and theoretical frameworks is more than an intellectual curiosity, as they have influential roles in reflecting and disseminating successful practices in mathematics educational contexts. Perhaps, as Ernst (1998) argues, we should accept educational research paradigms based on their outcomes in mathematics education, as judging them by their fruits and not by intentions might be the most seemly policy.

\section{References}

Anderson, J. R., Reder, L. M., \& Simon, H. A. (1996).Situated learning and education.Educational Researcher, 25(4), 5-11.

Apple, M. W. (1992). Do the standards go far enough? Power, policy, and practice in mathematics education. Journal for Research in Mathematics Education, 23(5), 412-431.

Apple, M. W. (2000). Mathematics reform through conservative modernization?Standards, markets, and inequality in education. In J. Boaler (Ed.), Multiple perspectives on mathematics teaching and learning (pp. 243-260). Westport, USA: Ablex.

Arthur, L. E. (1950).Diagnosis of disabilities in arithmetic essentials, Mathematics Teacher 43, 197-202.

Berlyne, D. E. (1965).Structure and direction in thinking. New York: Wiley.

Bernstein, B. (1996). Pedagogy, symbolic control, and identity. Bristol, PA: Taylor and Francis.

Bowers, C. A. (2008). Why a critical pedagogy of place is an oxymoron. Environmental Education Research, 14(3), 325 - 335.

Brighton, H. \& Todd, P.M. (2009).Situating Rationality. In P. Robbins \& M. Aydede (eds.) The Cambridge Book of Situated Cognition, (pp.3 22-346), New York, NY: Cambridge University Press.

Brown, A. L., \&Campione, J. C. (1994). Guided discovery in a community of learners.The MIT Press.

Brown, J. S., Collins, A., \&Duguid, P. (1989).Situated cognition and the culture of learning.Educational researcher, 18(1), 32-42.

Brown, J., \&Duguid, P. (1991). Organizational Learning and Communities of Practice: Toward a unified view of working, learning, and innovation. Organizational Science, 2 (1), 40-57.

Brown, J., \&Duguid, P. (1995).Stolen knowledge.Educational Technology,33(3), 10-15.

Brown, J., Collins, A. \&Duguid, P. (1989). Situated Cognition and the Culture of Learning. Educational Researcher, 18(1), 32-42.

Bruner, J. (1960). The process of education. Cambridge: Harvard University.

Bruner, J. 1990. Acts of Meaning. Cambridge: Harvard University Press.

Bruner, J. R., Goodnow, J. J., \& Austin, G. A. (1956).G.A (1956).A Study of Thinking. New York: John Wiley \& Sons.

Campbell, S. R. (2010). Embodied minds and dancing brains: New opportunities for research in mathematics education. In Theories of mathematics education: Seeking new frontiers (pp. 309-331). Berlin Heidelberg: Springer.

Chomsky N. (1959). Review of B. F. Skinner, Verbal Behavior.Language.35 (1), $26-58$.

Cobb, P. (1988). The tension between theories of learning and instruction in mathematics education.Educational psychologist, 23(2), 87-103.

Cobb, P. (2007). Putting philosophy to work.Coping with multiple theoretical perspectives.In F. K. Lester (Ed.), Second Handbook of Research on Mathematics Teaching and Learning (pp. 3-38). Greenwich, CT: Information Age Publishing.

Cobb. P,\& Hodge L.L. (2002). A relational perspective on issues of cultural diversity and equity as they play out in the mathematics classroom. Mathematical Thinking and Learning, 4(2-3), 249-284.

D'Ambrosio, U. (2001) Ethnomathematics Link between Traditions and Modernity. Rotterdam, Netherlands: Sense Publishers.

Delazer, M., Ischebeck, A. ,Domahs, F., Zamarian, L. Koppelstaetter, F. , Siedentopf, C.M. et al. (2005). Learning by strategies and learning by drill - Evidence from an fMRI study. Neuroimage, 25(3), 838-849.

Erlwanger, S. H. (1975). Case studies of children's conceptions of mathematics: I. Journal of Children's Mathematical Behavior, 1(3), 157-283.

Eisenberg, T. A. (1975). Behaviourism: the bane of school mathematics. International Journal of Mathematical Education in Science and Technology, 6(2), 163-171.

Ernest, P. (1992). The nature of mathematics: Towards a social constructivist account. Science \& Education, 1(1), 89-100.

Ernest, P. (1998). A postmodern perspective on research in mathematics education. In

A. $\quad$ Sierpinska and J. Kilpatrick Mathematics Education as a Research Domain: A Search for Identity (pp. 71-85), Kluwer 
Academic Publishers: Netherland.

Estes, W. K. \&Suppes, P. (1959). Foundations of Linear Models', in R. R. Bush and W. K. Estes (eds.), Studies in Mathematical Learning Theory, Stanford, California: Stanford University Press,.

Freire, P. (1990). The pedagogy of freedom: Ethics, democracy and civic courage. Lanham, MD: Rowman\& Littlefield.

Furuto, L. H. (2014). Pacific ethnomathematics: pedagogy and practices in mathematics education. Teaching Mathematics and Its Applications, 33(1), 1 of 12, doi:10.1093/teamat/hru009, hru009.

Gagne, R. M., (1965). The Conditions of learning. New York: Holt, Rinehart \& Winston.

Groth, R.E. (2007). Toward a conceptualization of statistical knowledge for teaching.Journal of Research in Mathematics Education, $38,417-437$.

Gardner, H. (1985). The mind's new science: A history of the cognitive revolution. New York: Basic Books.

Giddens, A. (1991). Modernity and self-identity: Self and society in the late modern age.Stanford, California: Stanford University Press.

Giroux, H. A. (1983). Theory and resistance in education: A pedagogy for the opposition. South Hadley, MA: Bergin \& Garvey.

Goodman, J. (1992, September). Towards a discourse of imagery: critical curriculum theorizing. In The Educational Forum, 56(3), 269-289.

Gruenewald, D.A. (2003), The best of both worlds: A critical pedagogy of place, Educational Researcher, 32(4), 3-12.

Habermas, J. (1984). The theory of communicative action. Beacon Press, Boston, MA.

Habermas, J. (1992). The philosophical discourse of modernity. Polity Press, Cambridge.

Howard, H. (2010). Neuromimetic Semantics: Coordination, quantification, and collective predicates. New York: Elsevier.

Howley, C. B., Howley, A. A., \& Huber, D. S. (2005). Prescriptions for rural mathematics instruction: Analysis of the rhetorical literature. Journal of Research in Rural Education, 20(7).Retrieved from http://www.jrre.psu.edu/articles/20-7.pdf

Kilpatrick, J. (1992). A history of research in mathematics education. In Grouws, D. A. (Ed.) Handbook of research on mathematics teaching and learning: A project of the National Council of Teachers of Mathematics, (pp. 3-38). New York, NY: Macmillan.

Kincheloe, J. L. (2005). Critical constructivism primer. New York: Peter Lang.

Kirschner, P. A., Sweller, J., and Clark, R. E. (2006) Why minimal guidance during instruction does not work: An analysis of the failure of constructivist, discovery, problem-based, experiential, and inquiry-based teaching. EducationalPsychologist 41(2) 75-86

Klein, P. D. (2007). The challenges of Scientific literacy: From the viewpoint of second-generation cognitive science. International Journal of Science Education,28(2), 143-178.

Knapp, C. 2007. Place-based curricular and pedagogical models: my adventures in teaching through community contexts. In Gruenewald, D. and Smith, G. Mahwah (Eds.) Place-based education in an era of globalization: local diversity. New Jersey: Erlbaum.

Lave, J., \& Wenger, E. (1991). Situated learning: Legitimate peripheral participation. Cambridge, UK: Cambridge University Press.

Lee, K., Lim, Z.Y., Yeong, S.H.M. Ng, S.F., Venkatraman, V., and Chee M.W.L. (2007). Strategic differences in algebraic problem solving: Neuroanatomical correlates Brain Research 1155, 163-171.

Lerman, S. (1996).Intersubjectivity in mathematics learning: A challenge to the radical constructivist paradigm? Journal for Research in Mathematics Education, 27(2), 133-150.

Lester, F. K. (2010). On the theoretical, conceptual, and philosophical foundations for research in mathematics education.In B. Sriraman and L. English (Eds.) Theories of mathematics education (pp. 67-85). Berlin Heidelberg: Springer.

Loveland, E. (2003). Achieving academic goals through place based education. Rural Roots, 4(1), 5-11.

Lund, D.E. (2003). Educating for Social Justice: making sense of multicultural and antiracist theory and practice with Canadian teacher activists.Intercultural Education, 14(1), 3-16.

Lyotard, J. F. (1997). The postmodern condition: A report on knowledge [La condition postmoderne: rapport sur le savoir]. Manchester: UK, Manchester University Press.

Magala.S. (2006). Critical theory: 15 years later. Critical Perspectives on International Business. 2(3), 183 - 194.

Martin, D. (2010, March). Not-so-strange bedfellows: Racial projects and the mathematics education enterprise. In Proceedings of the Mathematics Education and Society 6th International Conference (pp. 57-79).

Mayer, R. E. (1996). Learners as information processors: Legacies and limitations of educational psychology's second...Educational psychologist, 31(3-4), 151-161.

Moreno-Armella, L., \&Waldegg, G. (1993).Constructivism and mathematical education.International Journal of Mathematical Education in Science and Technology, 24(5), 653-661.

Nagataki, S., \& Hirose, S. (2007). Phenomenology and the third generation of cognitive science: towards a cognitive phenomenology of the body. Human Studies, 30(3), 219-232.

Nola, R. (1997). Constructivism in science and science education.Science and Education, 6, 55-83.

Novak, J. D. (1980). Progress in application of learning theory. Theory into Practice, 19(1), 58-65.

Oakes, J., Muir, K. \& Joseph, R. (2000).Coursetaking and achievement in mathematics and science: Inequalities that endure and change. Madison, WI: National Institute of Science Education.

Palincsar, A. S. (1998). Social constructivist perspectives on teaching and learning.Annual Review of Psychology, 49, 345-375.

Pass, S. (2004). Parallel paths to constructivism. Greenwich: Connecticut, Information Age Publishing.

Piaget, Jean. (1950). The Psychology of Intelligence. New York: Routledge.

Piaget, J., \&Inhelder, B. (1969).The psychology of the child.Basic Books.

Poirier, B. A. (2004). The pedagogy of place: A naturalistic exploration of river as teacher. Unpublished Master of Arts dissertation, University of Toronto.

Polya, G. (1957). How to Solve It: a new aspect of mathematical method, ed. London: Penguin. 
Putnam, R. T., \&Borko, H. (2000). What do new views of knowledge and thinking have to say about research on teacher learning? Educational Researcher, 29 (1), 4-15.

Pyle, R. M. (2001). The rise and fall of natural history.People and Nature, 20 (4), 16-23.

Radatz, H. (1979). Error analysis in mathematics education.Journal for Research in Mathematics Education 10 (3), 163-172.

Raffan, J. (1993). The experience of place: Exploring land as teacher. Journal of Experiential Education, 16(1), $39-45$.

Roberts, G. H. (1968). The failure strategies of third grade arithmetic pupils, Arithmetic Teacher 15(5), 442-446.

Rowlands, S., \& Carson, R. (2001). Contradictions in the constructivist discourse. Philosophy of Mathematics Education Journal. 14. Retrieved November 2, 2014, from http://www.people.ex.ac.uk/PErnest/pome14/rowlands.pdf

Scardamalia, M., \&Bereiter, C. (1994).Computer support for knowledge-building communities. The Journal of the Learning Sciences, 3(3), 265-283.

Schoenfeld, A. H. (Ed.). (1987). Cognitive science and mathematics education.Psychology Press.

Showalter, D. A. (2013). Place-based mathematics education: A conflated pedagogy?.Journal of Research in Rural Education, 28(6), $1-13$.

Skinner, B. F. (1953). Behaviourism.Science and Human Behaviour.

Skinner, B. F. (1954). The science of learning and the art of teaching. Cambridge, Mass, USA, 99-113.

Skinner B.F. (1957). Verbal behavior. New York: Appleton-Century-Crofts.

Skinner, B. F. (1985). Cognitive science and behaviourism.British Journal of Psychology, 76(3), 291-301.

Smith, G. A. (2002). Going local.Educational Leadership, 60 (1)30-33.

Smith, G. A. (2007). Place-based education: breaking through the constraining regularities of public school. Environmental Education Research, 13(2), 189-207.

Smith, J. P.; DiSessa, Andrea. A. \& Rochelle, Jeremy (1994). Misconceptions Reconceived: A Constructivist Analysis of Knowledge in Transition, 114-163.Chicago

Skovsmore, O. \& Valero, P. (2008).Democratic access to powerful mathematical ideas.in L.D. English (ed.), Handbook of International Research in Mathematics Education (pp. 383-408), Lawrence Erlbaum, Mahwah, NJ.

Staver, J. R. (1998). Constructivism: Sound theory for explicating the practice of science and science teaching. Journal of Research in Science Teaching, 35(5), 501-520.

Suppes, P. (1975). From behaviorism to neobehaviorism.Theory and Decision, 6(3), 269-285.

Sweller, J. (1994).Cognitive load theory, learning difficulty, and instructional design.Learning and instruction, 4(4), 295-312.

Tall, D. (2013).How humans learn to think mathematically: exploring the three worlds of mathematics. Cambridge University Press, London.

Thompson, J. M. (1914). Post-Modernism, TheHibbert Journal. 12(4), 733.

Thorndike, E. (1922). The psychology of arithmetic. New York, USA: Macmillan.

Valero, P. (2004). Socio-political perspectives on mathematics education. In P. Valero \& R. Zevenbergen (Eds.), Researching the socio-political dimensions of mathematics education (pp. 5-23). Dordrecht, The Netherlands: Kluwer.

Van Hiele, P. M., \& Van Hiele-Geldof, D. (1958).A method of initiation into geometry at secondary schools.In H. Freudenthal (Ed.), Report on methods of initiation into geometry (pp. 67-80). Groningen, Netherlands: J. B. Wolters.

Von Glasersfeld, E. (1990). An exposition of constructivism: Why some like it radical. In R. D. Davis, In C. A. Maher, \& N. Noddings (Eds.), Constructivist views on the teaching and learning of mathematics (JRME Monograph 4) (pp. 19-29). Reston, VA, USA: NCTM.

Von Glasersfeld, E. (1991). Radical constructivism in mathematics education. Dordrecht, The Netherlands: Kluwer. Von Glasersfeld, E. (1995). Radical constructivism: A way of knowing and learning. London, UK: Falmer Press. Watson, J. B. (1926). Behaviourism: a psychology based on reflex-action. Philosophy, 1 (04), 454-466.

Wenger, E. (1998). Communities of Practice: Learning, meaning, and identity. Cambridge, Cambridge University Press.

Woodhouse, J.L., \& Knapp, C.E., (2000). Place-based curriculum and instruction: outdoor and environmental education approaches, Digest EDO-RC-00-6, Charleston, West Virginia, ERIC Clearinghouse on Rural Education and Small Schools, Appalachia Educational Laboratory. 